\title{
Calímaco. Epigramas de Calímaco. Tradução, introdução e notas de Guilherme Gontijo Fores; revisão de tradução João Angelo Oliva Neto. Belo Horizonte: Autêntica Editora, 2019, 176 p.
}

Rafael Guimarães Tavares da Silva 1 ${ }^{1}$ Universidade Federal de Minas Gerais, Belo Horizonte, Minas Gerais, Brasil

A biblioteca brasileira de textos clássicos conta com uma recente e excelente contribuição no livro intitulado Epigramas de Calímaco, publicado pela editora Autêntica no final de 2019. Resgatando a obra epigramática desse poeta alexandrino, cuja vida se desenrolou aproximadamente entre os anos de 310-240 a.C., Guilherme Gontijo Flores propõe uma tradução de Calímaco com o objetivo de fazer "um diálogo poético", no qual a filologia é empregada apenas para "produzir poesia", para realizar aquilo que ele considera "ser a tarefa crítica de toda tradução poética" (Flores (f), 16). Antes de passarmos a uma breve análise crítica do resultado de sua proposta e de reflexões que a mesma oferece ao classicista tradutor de poesia na contemporaneidade, situemos um pouco o leitor com relação a Calímaco e a Guilherme Gontijo Flores no âmbito da produção em língua portuguesa no Brasil.

Se é verdade que Calímaco permanece para o leitor brasileiro uma espécie de "ilustre desconhecido", essa imagem tem sido pouco a pouco transformada por um esforço consciente de classicistas dedicados ao estudo de sua obra no país. Conhecido tradicionalmente pela locução poeta doctus, Calímaco costuma ser avaliado (de forma negativa muitas vezes, é preciso dizer) com 
mais ênfase no adjetivo doctus do que no substantivo poeta: numa atitude que remonta aos esquemas de história da arte esboçados por Winckelmann (orig. 1755) e aplicados à produção poética grega antiga por autores como Schiller (orig. 1795) e Schlegel (orig. 1795), o período helenístico (323-31 a.C.) entrou em certa historiografia da literatura clássica como uma época de decadência, na qual a erudição excessiva teria esvaziado o sentido vital da poesia. ${ }^{1}$ Em que pese a influência desse tipo de construto teórico na constituição e valorização de um cânone literário clássico, é inegável que a produção poética helenística foi continuamente reconhecida pelo menos como uma das principais fontes para a produção poética latina de autores da grandeza de Virgílio, Horácio, Propércio e Ovídio, angariando com isso uma das mais perenes razões para que jamais se deixasse completamente de lado o estudo dos poetas helenísticos.

O Brasil, contudo, tem testemunhado nos últimos anos uma virada de interesse pela poesia de Calímaco e de contemporâneos seus como Teócrito e Apolônio de Rodes. Desde 2007, por exemplo, o Departamento de Letras Clássicas e Vernáculas da Faculdade de Filosofia, Letras e Ciências Humanas da Universidade de São Paulo tem organizado as Semanas de Estudos Helenísticos, evento que atualmente se encontra em sua sexta edição. Além de gerar a publicação de estudos acadêmicos especificamente dedicados à produção helenística (Oliva Neto), esse tipo de iniciativa ajuda ainda a divulgá-la para um público mais amplo. Como reflexo desse mesmo movimento, o número de traduções, comentários e estudos das obras desses autores tem aumentado sensivelmente em âmbito acadêmico, como os trabalhos recentes de Erika Werner (2012), Érico Nogueira (2012) e Douglas Silva (2014), para citar apenas alguns exemplos, podem com riqueza testemunhar.

\footnotetext{
1 Uma representação típica da atitude mantida pela historiografia clássica oitocentista com relação a Calímaco e aos poetas helenísticos pode ser encontrada, por exemplo, no célebre manual de John Edwin Sandys (105-143).
}

Cad. Trad., Florianópolis, v. 40, $\mathbf{n}^{0}$ 2, p. 348-364, mai-ago, 2020. 
Coroando esse desabrochar da poesia helenística no Brasil, Guilherme Gontijo Flores lançou sua versão poética dos epigramas de Calímaco no final de 2019. O estudioso, além de professor de latim e, eventualmente, de grego na UFPR, tem uma já considerável obra de tradução, pela qual tem sido frequentemente premiado. Para ficar apenas no campo de textos antigos, verteu para o português as elegias de Sexto Propércio (Flores (a)), as odes de Horácio (Flores (b)), alguns dos poemas contidos na coletânea Por que calar nossos amores? (Carvalho) e os "fragmentos completos" de Safo (Flores (c)). Além disso, já publicou seis livros de poesia - sendo o último deles, carvão: capim (Flores (d)), um dos finalistas no prêmio Jabuti de 2019 na categoria Poesia -, um romance e uma vasta produção crítica mantida no website Escamandro. Trata-se, portanto, de um verdadeiro polímata com múltiplas áreas de interesse e uma atuação incansável em prol da divulgação dos estudos clássicos, da literatura e da poesia de modo geral no Brasil.

Calímaco, no entanto, não ocupa para Flores uma posição qualquer no âmbito da historiografia literária. Segundo o esclarecimento que o tradutor oferece em sua "Introdução" ao volume:

[T]rata-se do poeta mais importante do período helenístico, o catalisador e organizador de tendências crescentes numa poética cada vez mais distante da poesia homérica, da lírica arcaica (Safo, Alceu, Píndaro, Arquíloco, etc.) e das tragédias clássicas (Ésquilo, Sófocles, Eurípides). Foi essa a época que, pela primeira vez na história do ocidente, parecia não ver no texto escrito apenas letra morta, mas a potencialidade de toda poética; o período helenístico é o nascimento da filologia, o amor ao discurso. (Flores (f), 9).

Em outras palavras, Calímaco representa um dos principais nomes responsáveis por uma atitude radicalmente nova perante a 
materialidade da escrita: valorizando sua dimensão de jogo, de incerteza, de iterabilidade (ainda que sempre em diferença consigo), não é à toa que os poetas helenísticos, e todos aqueles que foram direta ou indiretamente influenciados por eles, passaram a estimar tanto o epigrama. Originalmente textos preparados para inscrição em pedra ou madeira, servindo sobretudo em lápides funerárias, ex-votos nos templos e ditos sapienciais em monumentos públicos, os epigramas adquiriram pouco a pouco um estatuto poético destacado justamente a partir do momento em que as implicações de sua dimensão material passaram a ser vistas em toda a sua potencialidade disruptiva: é certo que isso teve início sob a chancela de um grupo social enriquecido que encomendava a poetas de destaque textos bem acabados para serem inscritos em seus próprios monumentos (Flores (f), 12), mas pouco a pouco o interesse estético começou a ultrapassar o protocolo linguístico e a inscrição passou a se anunciar ela própria como monumento, isto é, como algo feito para durar.

Extrapolando o que é sugerido por Flores em sua breve "Introdução", acreditamos ser possível defender que a poesia helenística, especialmente na produção de Calímaco, prenuncia muito daquilo que será valorizado por uma geração recente de pensadores sob o nome de "escritura" (pensamos aqui sobretudo nas sugestões de Jacques Derrida): singularidade e iterabilidade, localização precisa no tempo e no espaço - ainda que aberta o bastante para manter sua legibilidade -, o epigrama helenístico se revela uma espécie de enigma nas fronteiras entre a biografia (histórica), a ficção (poética) e a reflexão (filosófica). Ou seja, irrompe deliberadamente como escritura. A guisa de exemplo disso, que se leve em conta o seguinte epigrama de Calímaco:

Alguém contou teu fado, Heráclito, e uma lágrima

caiu de mim; lembrei como nós dois

nas conversas deitávamos o sol. Mas tu,

vindo de Halicarnasso, agora és cinza; 
porém teus rouxinóis ainda vivem onde

Hades, raptor de tudo, não os toca.

(Calímaco, Epigramas 2, trad. Guilherme Gontijo Flores). ${ }^{2}$

Singularidade: é de nosso interesse saber que o poema provavelmente é dedicado a Heráclito de Halicarnasso, autor do epigrama 7.465 da Antologia Palatina, amigo de Calímaco e autor de versos para os quais o nome de Rouxinóis [Ājóves] certamente tinha alguma importância. Iterabilidade: das experiências compartilhadas num saudoso passado por dois amigos no âmbito desse poema, permanece apenas cinza - pois tal é o destino dos mortais -, contudo, o ser humano é capaz de se dedicar àquilo que transcende sua mortalidade. Tais são os rouxinóis de Heráclito, aves que adquirem na tradição poética ocidental um lugar de relevo por seu canto lamentoso e que se tornam símbolos de uma determinada concepção de poesia (Silva 3). A própria sobrevivência material do poema de Calímaco, no entanto, é o mais evidente símbolo da lógica da escritura: localizado precisamente no tempo e no espaço, ele se revela aberto o bastante para se manter legível em toda a sua potência até os dias de hoje, concretizando aquilo que ele próprio de certa forma anuncia: viver onde Hades, raptor de tudo, não é capaz de tocar. Único, mas repetível.

É por isso que ainda durante o próprio período helenístico, essa poética pouco a pouco ganhou autonomia para se desvincular da realidade biográfica e histórica. Dessa forma, tornou-se "então possível escrever epigramas fictícios, que jogassem com suas possibilidades no mundo real" (Flores (f), 13). Ou seja, para além

${ }^{2}$ Os textos do original grego citados ao longo do presente texto são extraídos da edição consultada (Flores (e)), segundo as opções de Guilherme Gontijo Flores,

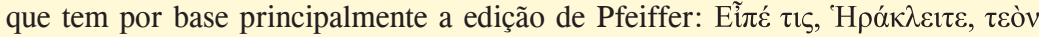

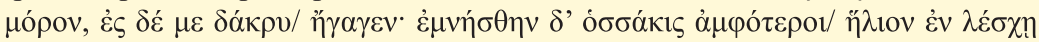

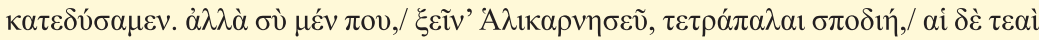

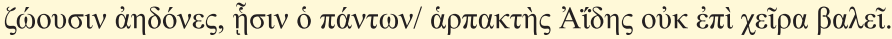

Cad. Trad., Florianópolis, v. 40, n 2, p. 348-364, mai-ago, 2020. 
de uma ancoragem na realidade de fatos históricos, os epigramas se converteram em formas poéticas breves e pungentes o bastante para atrair leitores interessados neles justamente por essas características formais. Com isso, tornava-se possível recorrer a eles para a exposição de uma poética alternativa àquelas mais tradicionalmente desenvolvidas pelos gregos dos períodos arcaico e clássico. Um belo exemplo disso seria o seguinte dístico de Calímaco:

Tão conciso o estrangeiro, que sua parca epígrafe

'Téris, o de Aristeu, cretense' é longa.

(Calímaco, Epigramas 11, trad. Guilherme Gontijo Flores). ${ }^{3}$

Tal como sugerido na nota do tradutor, provavelmente se trata aqui de um epigrama fúnebre fictício. Na versão em português, tentou-se manter a ambiguidade do termo grego sýntomos e que acreditamos ser responsável pela graça jocosa do epigrama: afinal, o estrangeiro é "conciso" de discurso ou de estatura? As duas leituras parecem igualmente possíveis, pois esse breve epitáfio se anuncia como longo demais, a um só tempo, tanto para representar a fala breve do defunto quanto para cobrir seu corpo diminuto. Além disso, vale notar que esse tipo de epigrama parece cumprir um papel programático no âmbito da obra de Calímaco, uma vez que a concisão desempenha uma função primordial em sua poética.

A título de exemplo, que se leve em conta o seguinte epigrama. No grego de Calímaco, nós temos o seguinte:

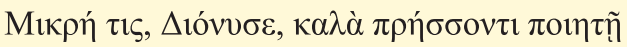

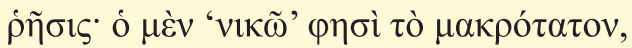

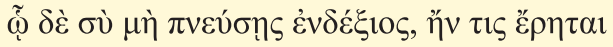

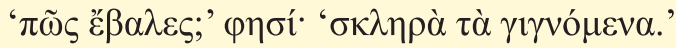

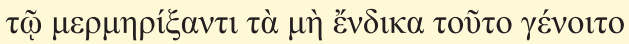

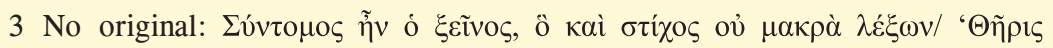

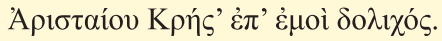

Cad. Trad., Florianópolis, v. 40, n 2, p. 348-364, mai-ago, 2020. 


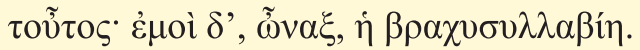 (Calímaco, Epigramas 8 Pfeiffer).}

Já no português de Flores:

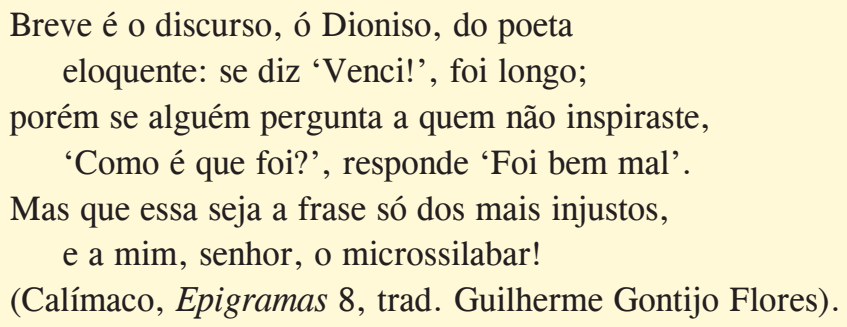

Tal como sugere o tradutor em seu comentário a esse poema, o

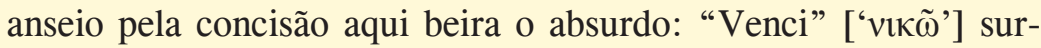
ge como uma expressão longa demais para o poeta efetivamente eloquente, afinal, a eloquência aí equivale à capacidade de dizer o máximo com o mínimo, ou seja, de se revelar "microssilabar" (um neologismo em português que bem faz ecoar o neologismo em grego antigo, $\beta \rho \alpha \chi v \sigma v \lambda \lambda \alpha \beta i ́ \eta)$. Esse poema é ainda mais interessante para nossa exposição aqui, uma vez que também exemplifica o que havíamos destacado da importância que a escritura ganha no âmbito da poética calimaqueana: singular e iterável, localizado num contexto específico, mas também legível para além desse contexto, tal epigrama se converte em espaço para uma reflexão de si em que vida de poeta e obra poética parecem se confundir.

O aspecto lúdico de uma espécie de "escrita de si" na produção de Calímaco funciona muito produtivamente. Além dos inúmeros textos em que uma persona poética emerge com reflexões de caráter metapoético - numa espécie de gesto autoafirmativo muito característico de poetas com tendências críticas, como é o caso do autor em questão (Silva, 101) -, há ainda uma série de menções no âmbito de sua obra cujas dimensões autobiográficas parecem inquestionáveis. Ainda que a tentativa de constituir uma biografia 
de Calímaco a partir das fontes antigas inevitavelmente incorra no "ciclo eterno e problemático obra-biografia-obra" (Silva, 101), o autor parece surgir em trechos emblemáticos de sua produção como personagem construído discursivamente: exibindo-se no momento mesmo de construção do discurso, enquanto indaga a própria subjetividade e se posiciona de forma crítica perante seus modos de representação, Calímaco antecipa algumas tendências da ficcionalização de si que mais tarde a literatura latina encontraria em Ovídio (se seguirmos as interpretações de Júlia Avellar), a literatura grega em Luciano (segundo Vincent Colonna) e, muitos séculos depois, a própria literatura contemporânea na produção de autores como João Gilberto Noll, Fernando Vallejo, Washington Cucurto e Bernardo Carvalho. ${ }^{4}$

Levemos em conta aquele que é considerado por muitos estudiosos da obra calimaqueana seu (brevíssimo) auto-epitáfio:

Passas na tumba do Batíada, perito

em verso e em repartir sorriso em vinho.

(Calímaco, Epigramas 35, trad. Guilherme Gontijo Flores). ${ }^{5}$

Ainda que se destaque pela ausência do nome próprio, esse epitáfio faz referência a um "Batíada", isto é, a um filho de Batos (nome do pai de Calímaco), salientando sua perícia no canto e sua propensão ao riso alegre em meio ao consumo de vinho. Além de constituir uma evidente autoafirmação da persona poética, esse trecho inicia

${ }^{4}$ A referência à literatura contemporânea se dá aqui por meio da obra de Diana Klinger (2016), segundo a qual seria preciso compreender a autoficção como traço distintivo da produção literária dos últimos anos no Brasil e em outros países ocidentais. Segundo sua definição, contudo, não vemos por que motivo a ideia de autoficção não se aplicaria também ao que faz o próprio Calímaco em vários trechos de sua produção poética, como demonstraremos na sequência de nossa exposição. Acerca da dimensão de "autoficcionalidade" em textos de autores antigos, $c f$. Silva; Anjos, 2019.

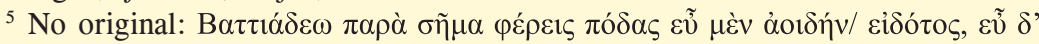

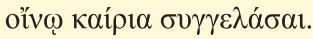


um complexo jogo metapoético com o próprio leitor, uma vez que se dirige a ele com palavras que podem ser traduzidas de forma mais literal do grego antigo da seguinte forma (em nossa tradução):

Trazes os pés ao túmulo do Batíada, daquele que o canto bem

sabe e que bem sabe a ocasião de gargalhar com o vinho.

Ora, os "pés” aí mencionados são tanto os do passante que por ventura se dirija às proximidades daquela tumba para apreciá-la quanto os pés do dístico elegíaco que viessem a ser cantados quando neles pousasse os olhos esse mesmo passante, então convertido em leitor do poema. O jogo metapoético, com a autoafirmação de cunho (auto)biográfico e com o jogo do qual inevitavelmente participa também o leitor, é riquíssimo e exemplifica de forma paradigmática a complexidade obtida por Calímaco com tão poucos versos.

Muitos outros trechos poderiam ser citados aqui para corroborar o que temos afirmado (além de inúmeros epigramas, também o prólogo dos Aetia e o trecho final do Hino a Apolo, ambos traduzidos por Flores num anexo ao volume). Por questões de espaço, contudo, consideremos encerrada nossa breve análise crítica dos méritos que a tradução de Guilherme Gontijo Flores obteve a partir de seu efetivo diálogo poético com Calímaco. Antes de encerrar nosso texto, no entanto, gostaríamos de fazer aqui algumas observações críticas pontuais ainda dedicadas ao diálogo poético entre Flores e Calímaco a partir da tradução que aquele faz deste, à luz de suas possíveis implicações para o campo dos estudos clássicos no Brasil.

Em sua "Introdução" aos epigramas de Calímaco, o tradutor afirma o seguinte:

Temos no Brasil alguns estudos sobre sua obra, que ficam restritos ao público dos Estudos Clássicos; também já cir- 
cularam algumas traduções esparsas de epigramas, hinos e fragmentos, que podem ser vasculhadas em revistas especializadas. Em todas elas, há uma fartura de comentários históricos, literários e antropológicos que podem interessar mais ao leitor especializado. (Flores (f), 12).

Pouco depois, ele diz ainda que até onde tem conhecimento, a sua seria a primeira tradução completa dos Epigramas de Calímaco em língua portuguesa. Como já tivemos ocasião de mencionar anteriormente, Douglas Silva defendeu em 2014 um mestrado e sua dissertação - disponibilizada gratuitamente na internet desde então - trazia um capítulo em que todos os epigramas calimaqueanos eram apresentados em grego antigo e em sua própria versão para o português. Não gostaríamos de implicar aqui com esse lapso ligeiro por parte do estudioso, na dimensão filológica de sua atividade, ainda mais porque ele próprio parece sugerir as razões para o mesmo: Flores afirma que fez uma primeira versão dos poemas ainda em 2009, quando ministrou uma disciplina optativa sobre poesia helenística no curso de Letras da UFPR, e deixou-os depois "horacianamente descansar na gaveta” (Flores (f), 16). Na sequência, o estudioso afirma o seguinte:

Consultei algumas edições e comentários mais famosos, como de Pfeiffer e de Gow e Page, certamente não todos, e não segui nenhum exclusivamente; também consultei versões para algumas línguas: a de Cahen (francês), Mair (inglês), Trypanis (inglês), Redondo (espanhol), Castillo (espanhol), Asper (alemão) e Giannes Dallas (grego moderno), e todos guiaram diversas soluções. (Flores (f), 17).

Como se vê, é de se imaginar que o tradutor tenha consultado o material à sua disposição por ocasião do primeiro momento em que se sentou para verter os versos de Calímaco e que, depois de deixá-los descansar na gaveta, não tenha voltado a consultar a bibliografia sobre o assunto. Do contrário, teria se deparado, 
pelo menos, com alguns dos poucos trabalhos brasileiros aqui mencionados por nós, os quais poderiam ter sido, contudo, de alguma ajuda no processo de releitura de suas próprias traduções, cerca de dez anos depois. Eles certamente teriam proporcionado ao tradutor o tipo de olhar distanciado tão importante numa revisão final, poupando-o de dois ou três deslizes relativamente graves em sua versão final.

O primeiro, e menos significante, deles encontra-se na interpretação oferecida em nota ao epigrama 45 :

'Foge, senão te prendem, Menécrates!', disse vinte de abril. E (quando?) dez de maio o boi já manso abraça o jugo. É bom, meu Hermes, é bom! E não reclamo os vinte dias.

(Calímaco, Epigramas 45, trad. Guilherme Gontijo Flores). ${ }^{6}$

A nota que se segue ao texto desse poema sugere o seguinte:

Neste epigrama, o poeta celebra como venceu um jovem amado num prazo de vinte dias, mas que então o outro cedeu ao casamento, como um touro que, por fim, aceita submeter-se ao jugo que carrega o arado" (Flores (e), 113, grifo nosso).

Ou muito nos enganamos, ou não se trata de todo de "ceder ao casamento", mas sim de fazer com que um jovem com potencial para se tornar, no âmbito da relação pederástica típica da sociedade grega antiga, um possível erốmenos [amado] não se prenda numa determinada relação de cunho afetivo ou social - talvez até desposando uma jovem -, a fim de que a persona poética possa vir a

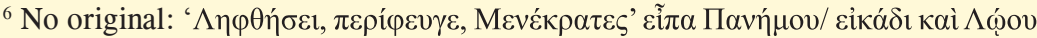

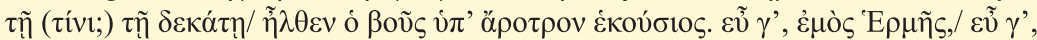

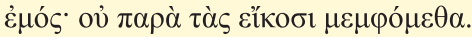

Cad. Trad., Florianópolis, v. 40, nº 2, p. 348-364, mai-ago, 2020. 
desfrutar junto dele, como efetivamente desfruta ao fim do poema, de uma relação pederástica enquanto seu erastếs [amante]. ${ }^{7}$

O segundo deslize encontra-se, a nosso ver, tanto na tradução quanto no comentário do epigrama 37 :

\author{
Menitas vem de Licto \\ para ofertar seu arco \\ dizendo: 'Toma o chifre \\ que dou com esta aljava, \\ Serápis; mas as setas \\ irão para os hespérides.' \\ (Calímaco, Epigramas 37, trad. Guilherme Gontijo Flores). ${ }^{8}$
}

Nesse poema, composto originalmente em dímetros iâmbicos e, por isso, vertido aí por Flores por versos de seis sílabas de cadência também jâmbica em português, não se trata daquilo que sugere o comentador, qual seja, de uma persona poética que oferece o arco de chifre e aljava para o deus, enquanto reserva as flechas para serem entregues ao povo de uma cidade da Líbia chamada Hespéride (Flores (e), 97). Toda a graça e pungência desse poema se perderiam caso se tratasse efetivamente de duas oferendas votivas em pé de igualdade: uma para o deus, a outra para o povo. Uma rápida consulta à tradução de Douglas Silva (121) demonstra isso com clareza:

$$
\begin{aligned}
& \text { O líctio Menitas } \\
& \text { estes arcos ofereceu } \\
& \text { e acrescentou 'Aqui, arco te } \\
& \text { dou e aljava, }
\end{aligned}
$$

\footnotetext{
${ }^{7}$ Para detalhes sobre essa complexa instituição social característica da sociedade grega antiga, cf. Jaeger, 2013, 239-50; Budelmann, 2009, 233; Meier, 2012, 105-6; p. 164-8.

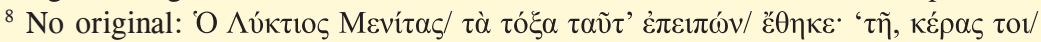

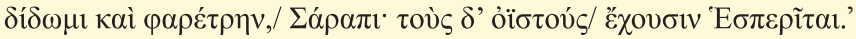

Cad. Trad., Florianópolis, v. 40, $\mathrm{n}^{0}$ 2, p. 348-364, mai-ago, 2020. 


\author{
Serápis. As flechas \\ ficaram com os hespérites.' \\ (Calímaco, Epigramas 37, trad. Douglas Silva).
}

Toda a graça do epigrama encontra-se justamente no fato de que a persona poética não podia entregar tudo o que vinha ofertar ao deus Serápis - isto é, suas armas de combate -, pois, tratando-se de arco-e-flecha, tinha voltado apenas com o arco e a aljava: afinal, as flechas ficaram como "oferenda" para os inimigos hespérites. Esse poema suscita ainda uma lição complementar sobre a importância de se levar em conta e respeitar tanto quanto possível os tempos verbais na hora da tradução, afinal, se Flores tivesse mantido no

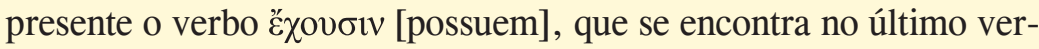
so do poema, talvez tivesse entrevisto que as flechas já não estavam mais em possessão daquele que vinha fazer a oferta do arco e da aljava ao deus Serápis, mas se encontravam com o povo inimigo.

O terceiro deslize, e que julgamos o mais complicado, encontra-se no início da coletânea, no brevíssimo epigrama 3:

Sem dar bom dia, ó negro peito, passa reto; sem ver o teu sorriso é bom meu dia.

(Calímaco, Epigramas 3, trad. Guilherme Gontijo Flores, grifo nosso).

Citemos aqui também a versão original de Calímaco, pois para a compreensão de uma expressão que vai ali traduzida em português por “ó negro peito" é imprescindível que se leve em conta o grego antigo:

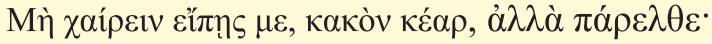

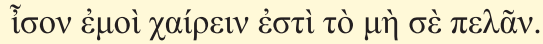
(Calímaco, Epigramas 3 Pfeiffer, grifo nosso).
} 


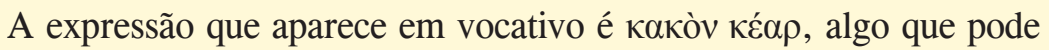
ser vertido literalmente (sem grandes prejuízos para a métrica seguida pelo poema de Flores) por "mau coração", sendo de se notar que Douglas Silva (105) a verteu ainda por "coração cruel”. A nuance negativa, no que tange à moral ou à aparência de algo caracterizado como kakòn, é óbvia para estudiosos do grego antigo, mas não se encontra nela qualquer sugestão de que se trate de uma característica cromática, relativa à cor negra. Como deve estar evidente para o leitor de língua portuguesa, a expressão "peito negro" comporta como primeiro e mais óbvio referente em português uma pessoa negra. Assim sendo, essa expressão, como forma de traduzir kakòn kéar, constitui, no melhor dos casos, um erro grave de tradução.

Como se vê a partir desses três exemplos, a tradução e os comentários que Guilherme Gontijo Flores oferece aos epigramas de Calímaco poderiam ter se beneficiado de uma breve consulta a - para além dos materiais nominalmente citados por ele (Flores (f), 17-18) - alguns dos estudos brasileiros que nos últimos anos têm sido dedicados à obra desse poeta alexandrino. Seu interesse muitas vezes de fato é primeiramente acadêmico, mas suas implicações para uma reflexão aprofundada sobre o objeto de que tratam é inegável.

Gostaríamos de encerrar aqui com a expressão mais sincera de nossa admiração pela excelência da poesia que esse verdadeiro poeta doctus tem obtido a partir de sua leitura criativa da tradição clássica. Seu Calímaco chega para dar ainda mais fôlego ao florescimento que os estudos helenísticos têm vivido no Brasil e acreditamos que ele possa se revelar uma excelente via de acesso à poesia grega antiga. Além disso, vale a pena expressar nosso reconhecimento pelo paradigma de intelectual que Guilherme Gontijo Flores tem delineado para o acadêmico contemporâneo: culto, crítico e criativo, envolvido ativamente na produção de conhecimento em nossa sociedade, esse classicista chega além dos limites da universidade.

E que seu diálogo poético com a tradição continue... 


\section{Referências}

Avellar, Júlia B. C. As Metamorfoses do Eu e do Texto. 320 f. Dissertação (Mestrado em Literaturas Clássicas e Medievais) - Faculdade de Letras Universidade Federal de Minas Gerais, Belo Horizonte, 2016.

Budelmann, Felix. "Anacreon and the Anacreontea." In: Budelmann, F. (Ed). The Cambridge Companion to Greek Lyric. Cambridge: Cambridge University Press, 2009. p. 227-239

Carvalho, Raimundo et al.. Por que calar nossos amores? Poesia homoerótica latina. Belo Horizonte: Autêntica Editora, 2017.

Colonna, Vincent. Autoficcion \& autres mythomanies littéraires. Auch: Tristam, 2004.

Flores, Guilherme Gontijo (a). Sexto Propércio: Elegias de Sexto Propércio. Org., trad., introd. e notas de Guilherme Gontijo Flores. Belo Horizonte: Autêntica Editora, 2014a.

Flores, Guilherme Gontijo (b). Uma poesia de mosaicos nas Odes de Horácio: Comentário e tradução poética. $414 \mathrm{f}$. Tese (Doutorado em Letras) - Faculdade de Filosofia, Letras e Ciências Humanas da Universidade de São Paulo, São Paulo, 2014b.

Flores, Guilherme Gontijo (c). Safo: Fragmentos completos. Tradução, introdução e notas de Guilherme Gontijo Flores. São Paulo: Editora 34, 2017.

Flores, Guilherme Gontijo (d). carvão: capim. São Paulo: Editora 34, 2018.

Flores, Guilherme Gontijo (e). Calímaco: Epigramas de Calímaco. Tradução, introdução e notas de Guilherme Gontijo Flores. Belo Horizonte: Autêntica Editora, 2019a. 
Flores, Guilherme Gontijo (f). "Introdução.”. In: Flores, Guilherme Gontijo. Epigramas de Calímaco. Tradução, introdução e notas de Guilherme Gontijo Flores. Belo Horizonte: Autêntica Editora, 2019b. p. 9-18.

Jaeger, Werner. Paideia: a formação do homem grego. Tradução de Artur M. Parreira. 6. ed. São Paulo: Editora WMF Martins Fontes, 2013.

Klinger, Diana. Escritas de si, escritas do outro: o retorno do autor e a virada etnográfica. 3. ed. Rio de Janeiro: 7Letras, 2016.

Nogueira, Érico. Verdade, contenda e poesia nos Idílios de Teócrito. 2012. 292 f. Tese (Doutorado em Letras Clássicas) - Faculdade de Filosofia, Letras e Ciências Humanas da Universidade de São Paulo, São Paulo, 2012.

Oliva Neto, João Angelo, (Org). I Semana de Estudos Helenísticos. São Paulo: Humanitas, 2010.

Pfeiffer, Rudolf, (Ed). Callimachus. 2 v. Oxford: Clarendon, 1953.

Sandys, John E. A History of Classical Scholarship. Vol. 1: From the Sixth Century B.C. to the End of the Middle Ages. Cambridge: University Press, 1903.

Schiller, Friedrich. Poesia ingênua e sentimental. Tradução de Márcio Suzuki. São Paulo: Iluminuras, 1991.

Schlegel, Friedrich. Sobre o estudo da poesia grega. Tradução de Constantino Luz de Medeiros. São Paulo: Iluminuras, 2018.

Silva, Douglas. Escrever, sobrescrever: metalinguagem nos epigramas de Calímaco. 140f. Dissertação (Mestrado em Letras) - Faculdade de Letras, Universidade Federal de Minas Gerais, Belo Horizonte, 2014.

Silva, Rafael; Anjos, Sara. "Entre o 'eu' e o 'outro' na ordem do discurso da Grécia antiga." Anais eletrônicos do Congresso Internacional ABRALIC 2019 (2): (2019): 2623-2631. 
Werner, Erika. Os Hinos de Calímaco: Poesia e Poética. São Paulo: Humanitas, 2012.

Winckelmann, Johann Joachim. Pensées sur l'imitation des oeuvres grecques en peiture et en sculpture. Tradução de Léon Mis. Paris: Aubier, 1990.

Recebido em: 29/01/2020

Aceito em: 06/04/2020

Publicado em maio de 2020

Rafael Guimarães Tavares da Silva. E-mail: gts.rafa@hotmail.com. ORCID: https://orcid.org/0000-0002-8985-8315. 